\title{
Feasibility Evaluation of Quinary Heterogeneous Reactive Extractive Distillation
}

\author{
D. Kang, ${ }^{\dagger}$ K. Lee, ${ }^{\ddagger}$ and Jae W. Lee ${ }^{* \dagger, \dagger}$ \\ ${ }^{\dagger}$ Department of Chemical and Biomolecular Engineering, Korea Advanced Institute of Science and Technology (KAIST), Daejeon \\ 305-701, Republic of Korea \\ ${ }^{\ddagger}$ Department of Chemical Engineering, The City College of New York, CUNY, New York, New York 10031, United States
}

Supporting Information

\begin{abstract}
This study addresses a feasibility evaluation method for the heterogeneous reactive extractive distillation of azeotropic quinary mixtures based on visualization in composition space. A critical composition region, that is, thermodynamically infeasible region for heterogeneous reactive extractive distillation, is determined by the constraint of reaction and phase equilibria. In addition, operating constraints are imposed on the feasibility evaluation in terms of the upper and lower internal reflux boundaries. Using these two kinds of feasibility constraints, we examine how the ethyl and isopropyl acetate reactive distillation systems, which cannot produce pure products because of four minimum-boiling azeotropes, lead to a full conversion and pure product recovery with the introduction of an external entrainer inducing $\mathrm{L}-\mathrm{L}$ splits. The pure acetate production in a single reactive extractive distillation column is possible because the composition trajectory approaches the desired region in composition space without being blocked by both the critical composition region and the infeasible region confined by the internal reflux boundaries.
\end{abstract}

\section{INTRODUCTION}

Reactive distillation provides economic advantages by intensifying reaction and distillation in a single process unit. The three main benefits of employing reactive distillation are the potentials for lower capital/operating costs, higher product yields, and the circumvention of phase equilibrium limitations such as azeotropes and distillation boundaries. ${ }^{1-6}$ The lower capital costs come from the small number of process units required because the separation and reaction operation units are integrated into a single reactive separation unit. Because the amount of heat utilities needed for the simplified process is much less than the conventional sequential reaction-separation scheme and the reaction heat can be used for separation, the operating costs are significantly reduced. Higher product yields are achieved by shifting the reaction equilibrium in the forward direction through the direct recovery of the products from the reaction section. The circumvention of phase equilibrium limitations is possible by reacting away azeotropes and crossing the distillation boundaries, as shown by previous graphical methods. $^{7-9}$

Despite these advantages, not many reactive distillation units have been put into commercial practice. After the success of the commercial methyl acetate process, ${ }^{10}$ reactive distillation became an attractive way to replace sequential reactionseparation processes. Several researchers have tried to produce pure ethyl and isopropyl acetates through reactive distillation. ${ }^{11-14}$ However, the reaction conversions and purities of the products were not high enough to produce pure products, and additional purification steps were required to separate the products from unreacted reactants. In other words, with a single reactive distillation unit, the full reaction conversion and recovery of pure products could not be achieved for the ethyl and isopropyl acetate production systems. The reasons these systems cannot produce pure products in reactive distillation columns were elucidated in a previous work using graphical interpretations. ${ }^{15}$

Thus, this study introduces an external heterogeneous entrainer to explore the possibility of achieving the full reaction conversion and recovery of pure products in the ethyl and isopropyl acetate production systems and aims at understanding how the full reaction conversion and recovery of pure products are achieved. The original reaction mixture forms a four-component system, but it is changed to a five-component system with an external extrainer. The five-component system requires a four-dimensional space and is not trivial to visualize in composition space.

Some pure products have been recovered in reactive extractive distillation by employing some entrainers that induce liquid-liquid (L-L) splits. ${ }^{16-21}$ However, without an understanding of why the limitation is circumvented, numerous trialand-error of experiments and simulations will be needed whenever reactive extractive distillation is applied to other reaction systems. One simple way to elucidate the behavior of reactive distillation is the graphical method. By visualizing the composition trajectory and infeasible regions where the composition trajectory cannot pass, the interactions between reaction and separation can be comprehended. However, although the geometric approach is one simple way to gain insight into both distillation and reactive distillation and although it has been studied for various systems, ${ }^{22-29}$ there have been few geometric studies of heterogeneous reactive

Received: February 7, 2014

Revised: June 27, 2014

Accepted: July 10, 2014

Published: July 10, 2014 
extractive distillation. Therefore, this work investigates how introducing an entrainer leads to complete reaction conversion and pure product recovery in heterogeneous reactive extractive distillation based on the concepts of a critical composition region and upper/lower internal reflux boundaries. To do this, the concepts derived from the four-component system ${ }^{15}$ are extended and applied to the five-component system by introducing an entrainer.

\section{FEASIBLE DIRECTION OF THE COMPOSITION TRAJECTORY IN REACTIVE EXTRACTIVE DISTILLATION}

A schematic diagram of reactive extractive distillation is shown in Figure 1. A general reactive extractive distillation column

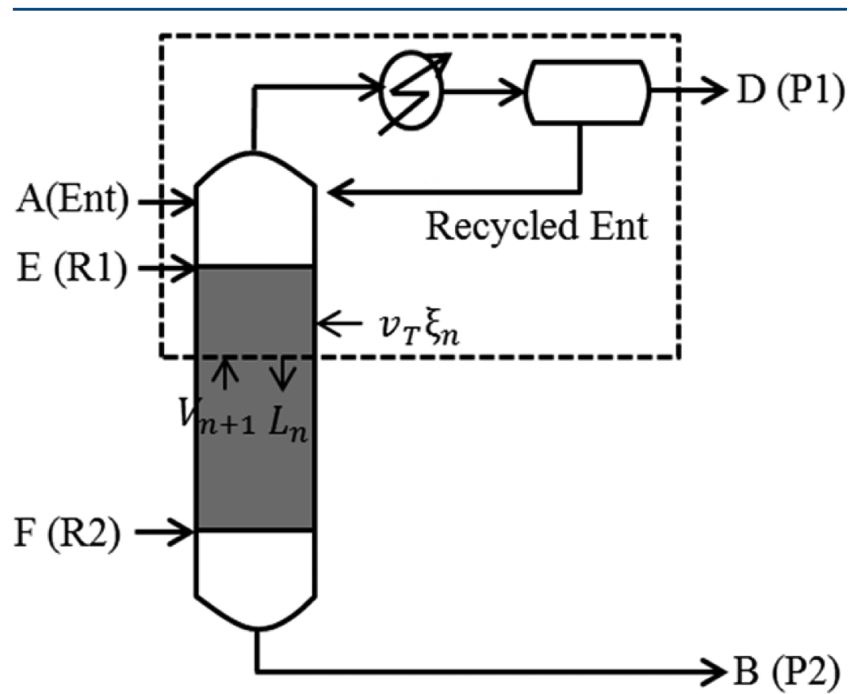

Figure 1. Schematic of a reactive extractive distillation column.

consists of three sections: nonreactive rectifying, stripping, and reaction sections between two feed streams. Heavy (R1) and light (R2) reactants are supplied to the top and bottom of the reaction section, respectively, thus causing the following liquidphase reaction in the reaction section

$$
\mathrm{R} 1+\mathrm{R} 2 \leftrightarrow \mathrm{P} 1+\mathrm{P} 2
$$

An entrainer (Ent) forms a minimum heterogeneous azeotrope with product P1 (normally water), and thus, this minimum heterogeneous azeotrope mixture is separated from the top of the column. After that, the minimum heterogeneous azeotrope of P1 and Ent is separated into a P1-rich phase and an Ent-rich phase from the decanter. The decanted Ent-rich phase is recycled to the column, and the P1-rich phase is recovered. To compensate for the loss of a small amount of Ent in the product streams of P1 and P2, Ent makeup (A) is supplied to the top of the column. Because almost-pure P1 is recovered from the decanter and all of the reactants are converted into products by the reaction, pure product P2 is naturally recovered from the bottom of the column through the nonreactive stripping section. It is assumed that the liquid composition of the reaction section corresponds to the reaction equilibrium and the vapor of the reaction section is phaseequilibrated with the liquid on each reactive stage.

In the visualized five-component space, the composition trajectory in the reaction section approaches the R1-P1-Ent ternary plane as the composition trajectory moves toward the upper feed stage, and thus, only R1, P1, and Ent remain at the top of the reaction section. Because R1-P1-Ent mixtures can be easily separated through the nonreactive rectifying section and decanter, pure P1 can be recovered from the decanter (see Figure 1).

The approach to the R1-P1-Ent ternary plane of the composition trajectory of the five-component system implies that R2 is completely consumed by the reaction. With the reaction stoichiometric feed provided to the column, $\mathrm{R} 1$ is also completely consumed by the reaction at the bottom of the reaction section. Therefore, the composition trajectory naturally approaches the $\mathrm{R} 2-\mathrm{P} 2-$ Ent ternary plane as the composition trajectory goes down to the lower stages. After reaching the R2-P2-Ent ternary plane, P2 is easily separated through the nonreactive stripping section and recovered from the bottom of the column. If the composition trajectory of the reactive extractive distillation moves in these two directions in composition space, the reactive distillation system can achieve full reaction conversion and produce pure products. Because a five-component system is visualized in four-dimensional space, one component is projected for visualization purposes using the equations $^{30}$

$$
\bar{x}_{n, k, \mathrm{comp}}=\frac{x_{n, \mathrm{comp}}}{1-x_{n, \mathrm{R} 1 \mathrm{orP} 1}}, \quad \bar{y}_{n, k, \mathrm{comp}}=\frac{y_{n, \mathrm{comp}}}{1-y_{n, \mathrm{R} 1 \mathrm{orP} 1}}
$$

where $n$ is the number of stages, $k$ is the projected component ( $\mathrm{R} 1$ or $\mathrm{P} 1)$, and comp represents the components other than the projected component. Through the projection, the fivecomponent system is converted into a projected fourcomponent system and is easily visualized in three-dimensional space. When the entrainer is selected as a projected component, the desired composition trajectory should approach the $\overline{\mathrm{R} 1}-\overline{\mathrm{P} 1}$ binary edge as it goes up to the upper stages and the $\overline{\mathrm{R} 2}-\overline{\mathrm{P} 2}$ binary edge as it goes down to the lower stages to achieve full reaction conversion and pure product recovery (Figure 2).

However, it is not necessary to evaluate both criteria to evaluate the feasibility of the quinary reactive extractive distillation. As explained above, if the stoichiometric amounts of reactants are supplied to the column and the composition trajectory reaches the $\overline{\mathrm{R} 1}-\overline{\mathrm{P} 1}$ binary edge at the top of the reaction section, the composition trajectory naturally reaches the $\overline{\mathrm{R} 2}-\overline{\mathrm{P} 2}$ binary edge at the bottom of the reaction section because $\mathrm{R} 1$ is completely consumed at the bottom of the reaction section. Therefore, to evaluate the feasibility of reactive extractive distillation, one must check whether the composition trajectory can reach the $\overline{\mathrm{R} 1}-\overline{\mathrm{P} 1}$ binary edge at the top of the reaction section for stoichiometric amounts of reactant feed.

\section{PRELIMINARY SELECTION OF ENTRAINER}

The criteria for the selection of a proper entrainer have been studied for both azeotropic distillation ${ }^{31}$ and reactive distillation. ${ }^{16,17,20,21,32}$ According to these criteria, the entrainer should form a minimum heterogeneous azeotrope with P1 and have a low solubility in P1. By forming a minimum heterogeneous azeotrope with $\mathrm{P} 1$, the entrainer can increase the relative volatility of $\mathrm{P} 1$, such that $\mathrm{P} 1$ can be recovered from the top of the column with the entrainer. Then, the P1-Ent mixture is sharply split into P1-rich and Ent-rich phases by a decanter. Because the solubility of the entrainer in the P1-rich phase determines the purity of the product, the entrainer should have a low solubility in the P1-rich phase. At the same time, the solubility of $\mathrm{P} 1$ in the entrainer-rich phase determines 


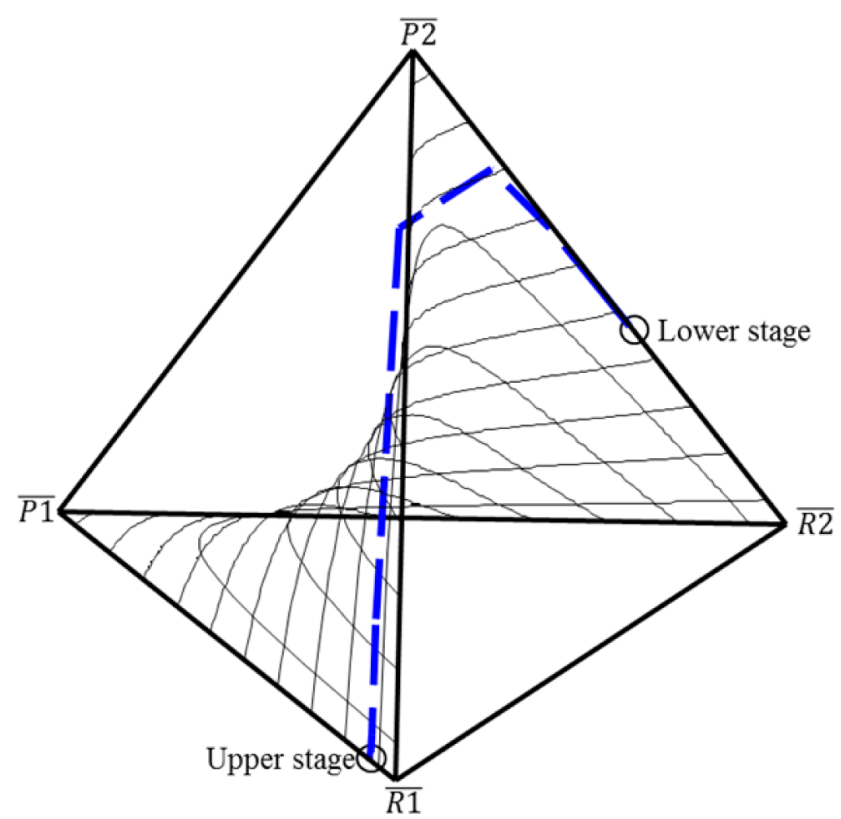

Figure 2. Desired composition trajectory in the Ent-projected composition space. The dotted blue curve represents a liquid composition trajectory from the bottom to the top stage of the reaction section. Solid curves form a reaction equilibrium surface for $\mathrm{R} 1+\mathrm{R} 2 \leftrightarrow \mathrm{P} 1+\mathrm{P} 2$.

the amount of the recycle stream from the decanter to the column, so P1 should also have a low solubility in the entrainerrich phase. Once a few candidates for entrainers have been selected, the next step is to apply the concepts of a critical composition region and upper/lower reflux boundaries to the feasibility evaluation to explore the possibility of obtaining pure products in a single reactive extractive distillation column.

\section{CRITICAL COMPOSITION REGION}

A critical composition region is a region where thermodynamic constraints imposed by the reaction and phase equilibria prevent the composition trajectory of the reactive extractive section from approaching the desired region that eventually leads to a pure product using $\mathrm{L}-\mathrm{L}$ decantation. The desired region is the $\mathrm{R} 1-\mathrm{P} 1$ binary edge in the quaternary reactive distillation system, and it is the R1-P1-Ent ternary plane in the quinary system. When the liquid composition of an arbitrary reactive stage lies closer to the desired region than its equilibrated vapor composition of the same stage, the composition profile cannot approach the desired region by moving up the reaction section. Thus, a critical composition region is defined as the group of specific liquid compositions whose equilibrated vapor compositions lie farther from the desired region than the liquid compositions. ${ }^{15,33}$ For the visualization of the critical composition region, a single component is projected in the four-component system (eq 2 ), and two components are projected in the five-component system using the equations

$$
\begin{gathered}
\overline{\bar{x}}_{n,(k 1, k 2), \mathrm{comp}}=\frac{x_{n, \mathrm{comp}}}{1-x_{n, k 1}-x_{n, k 2}}, \\
\overline{\bar{y}}_{n,(k 1, k 2), \mathrm{comp}}=\frac{y_{n, \mathrm{comp}}}{1-y_{n, k 1}-y_{n, k 2}}
\end{gathered}
$$

where $n$ is the number of stages, $(k 1, k 2)$ describes projected components, and comp represents the components other than the projected components.

In the four-component system, the approach to the purecomponent vertex in the projected ternary plane is equal to the approach to the binary edge between the vertex and the projected component in the original composition space. Therefore, when both the liquid mole fraction of P1 in the $\mathrm{R} 1$ projection and that of $\mathrm{R} 1$ in the $\mathrm{P} 1$ projection are larger than their equilibrated vapor mole fractions, the liquid composition is closer to the $\mathrm{R} 1-\mathrm{P} 1$ binary edge than the equilibrated vapor composition. Therefore, the criteria of the critical composition region in the four-component system are $\bar{x}_{n, \mathrm{R} 1, \mathrm{P} 1}>\bar{y}_{n, \mathrm{R} 1, \mathrm{P} 1}$ and $\bar{x}_{n, \mathrm{R} 1, \mathrm{P} 1}>\bar{y}_{n, \mathrm{R} 1, \mathrm{P} 1}$ from eq 2 . In summary, a critical composition region is defined as the region where projected liquid fractions relevant to the desired region are larger than their equilibrated vapor fractions in all of the relevant projections. It is noted that a critical composition region should satisfy both inequality constraints. Thus, if either the $\mathrm{R} 1$ or P1 vapor fraction is larger than its equilibrated liquid fraction in the projected plane, the composition trajectory can still approach the R1-P1 binary edge as it goes up to the upper stages. ${ }^{15,33}$

The R1-projected three-component plane is shown in Figure 3. The approach of the composition trajectory to point $\overline{\mathrm{P} 1}$ in

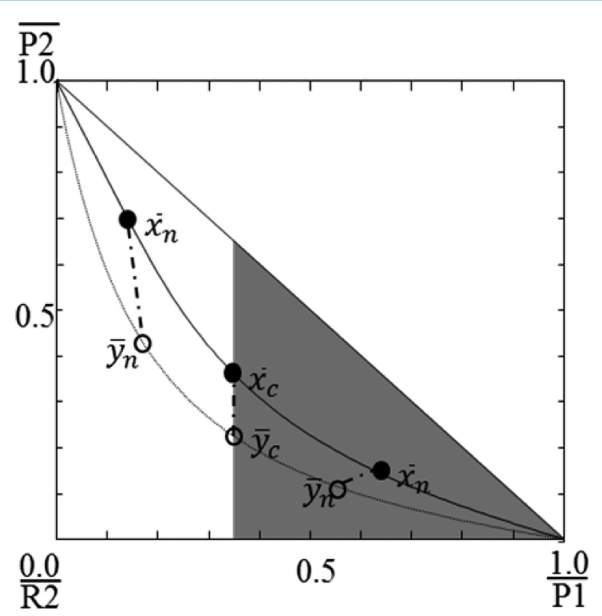

Figure 3. R1-projected ternary component plane with a shaded critical composition region; the solid curve represents liquid compositions at reaction equilibrium, and the dotted curve represents the equilibrated vapor compositions.

Figure 3 implies that the composition trajectory accesses the $\mathrm{R} 1-\mathrm{P} 1$ binary edge in the four-component space. As can be seen in Figure 3, a composition trajectory can no longer approach point $\overline{\mathrm{P} 1}$ in the shaded region where $\bar{x}_{n, \mathrm{R} 1, \mathrm{P} 1}$ is larger than $\bar{y}_{n, \mathrm{R} 1, \mathrm{P} 1}$.

After the critical composition region has been calculated in the projected three-component plane, the original compositions corresponding to the projected compositions are plotted in the quaternary composition space. Then, it is checked whether the critical composition region completely shades the R1-P1 binary edge. If this binary edge is completely shaded by the critical composition region, the composition profile has no chance to reach the R1-P1 binary edge in the four-component space. Therefore, this reaction-distillation integration cannot achieve full reaction conversion and pure product recovery thorough a double-feed reactive distillation column. 

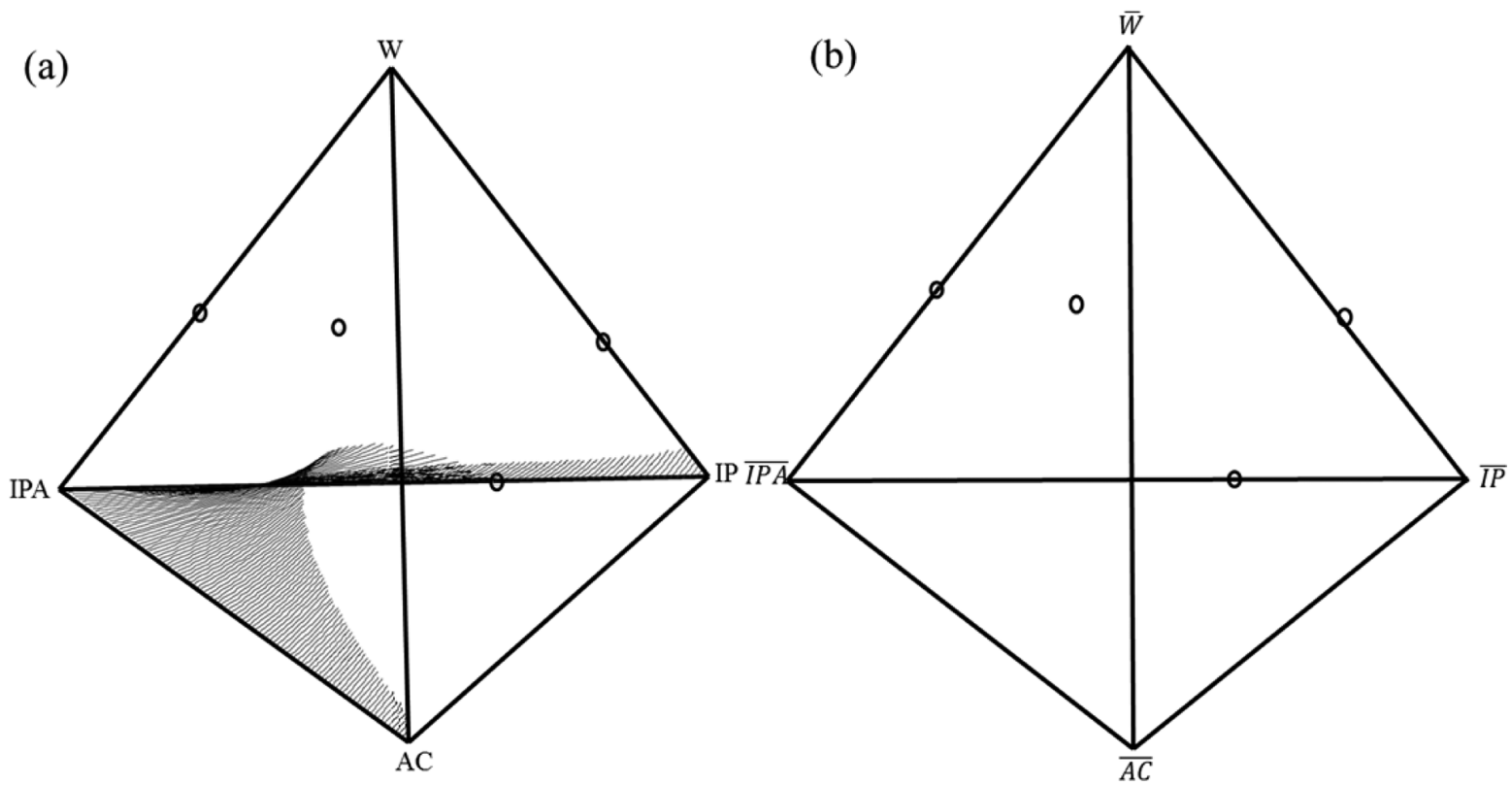

Figure 4. Critical composition region of the IPA system (a) without any entrainer and (b) with chloroform or $n$-hexane $\left(x_{\text {Ent }}=0.01-0.99\right)$. Open circles are azeotropes of the IPA system, and the shaded region describes the critical composition region.

In the five-component system, the approach of the composition trajectory to the pure-component vertex in the two-component-projected system is equal to the access to the ternary plane consisting of the vertex and two projected components in the original quinary composition space. Because the composition trajectory should reach the R1-P1-Ent ternary plane at the top of reaction section, the critical composition region in the five-component system should satisfy three criteria: $\overline{\bar{x}}_{n,(\mathrm{P} 1, \mathrm{Ent}), \mathrm{R} 1}>\overline{\bar{y}}_{n,(\mathrm{P} 1, \mathrm{Ent}), \mathrm{R} 1}, \overline{\bar{x}}_{n,(\mathrm{R} 1, \mathrm{Ent}), \mathrm{P} 1}>\overline{\bar{y}}_{n,(\mathrm{R} 1, \mathrm{Ent}), \mathrm{P} 1}$, and $\overline{\bar{x}}_{n,(\mathrm{P} 1, \mathrm{R} 1) \text {,Ent }}>\overline{\bar{y}}_{n,(\mathrm{P} 1, \mathrm{R} 1) \text {,Ent }}$. Compared with the two criteria of the four-component system, the introduction of a proper entrainer provides one additional constraint and a greater chance to decrease the critical composition region. To find the critical composition region in the five-component system, all reaction-equilibrated liquid compositions are evaluated with constant fractions of the entrainer from 0.01 to 0.99 . It is necessary for the desired region not to be completely shaded by the critical composition region to achieve pure product recovery through reactive extractive distillation with the selected entrainer.

One good example whose feasibility is restricted by the critical composition region is the isopropyl acetate (IPA) production system with the reaction

$$
\mathrm{AC}+\mathrm{IP} \leftrightarrow \mathrm{IPA}+\mathrm{W}
$$

where AC, IP, and $\mathrm{W}$ represent acetic acid, isopropyl alcohol, and water, respectively.

To evaluate the feasibility of IPA production in double-feed reactive distillation without an entrainer, the critical composition region of this system is calculated and plotted using the constraints $\bar{x}_{n, \mathrm{R} 1, \mathrm{P} 1}>\bar{y}_{n, \mathrm{R} 1, \mathrm{P} 1}$ and $\bar{x}_{n, \mathrm{P} 1, \mathrm{R} 1}>\bar{y}_{n, \mathrm{P} 1, \mathrm{R} 1}$ with the reaction equilibria data from previous works. ${ }^{34,35}$ The parameters for the nonrandom two-liquid (NRTL) equation are used from Aspen Plus and available with azeotropic information in Tables S1-S3 (Supporting Information). Because the relative volatility of IPA is larger than W and AC is less volatile than IP, R1 becomes AC and P1 becomes IPA in this system. According to the definition of the critical composition region, the group of liquid compositions which satisfy both $\bar{x}_{n, \mathrm{IPA}, \mathrm{AC}}>\bar{y}_{n, \mathrm{IPA}, \mathrm{AC}}$ and $\bar{x}_{n, \mathrm{AC}, \mathrm{IPA}}>\bar{y}_{n, \mathrm{AC}, \mathrm{IPA}}$ are plotted in Figure 4a. As can be seen from this plot, the critical composition region completely shades the AC-IPA binary edge. Therefore, the pure IPA production cannot be realized through double-feed reactive distillation.

To eliminate the critical composition region by introducing an entrainer, chloroform (Chl) and $n$-hexane (Hexane) are chosen as candidate entrainers. Because both $\mathrm{Chl}$ and Hexane increase the relative volatility of $\mathrm{W}$ by forming minimum heterogeneous azeotropes with $\mathrm{W}, \mathrm{P} 1$ becomes $\mathrm{W}$ instead of IPA in the five-component system. By using $\mathrm{Chl}$ as an entrainer, the criteria for the critical composition region are changed to $\overline{\bar{x}}_{n,(\mathrm{~W}, \mathrm{Chl}), \mathrm{AC}}>\overline{\bar{y}}_{n,(\mathrm{~W}, \mathrm{Chl}), \mathrm{AC}}, \overline{\bar{x}}_{n,(\mathrm{AC}, \mathrm{Chl}) \mathrm{W}}>\overline{\bar{y}}_{n,(\mathrm{AC}, \mathrm{W}), \mathrm{Ch} l}$ and $\overline{\bar{x}}_{n,(\mathrm{AC}, \mathrm{W}), \mathrm{Chl}}>\overline{\bar{y}}_{n,(\mathrm{AC}, \mathrm{W}), \mathrm{Chl}}$. From the calculation based on the reaction and phase equilibria, there is no critical composition region in the IPA quaternary mixture with $\mathrm{Chl}$ (Figure $4 \mathrm{~b}$ ) when the constant fractions of $\mathrm{Chl}$ are $0.01-0.99$. Similarly, the Hexane case also completely eliminates the critical composition region. The parameters of the NRTL equation and the calculated azeotropes in these two quinary systems can be found in Tables S1-S3 (Supporting Information).

\section{INFEASIBLE REGION BY REFLUX BOUNDARIES}

Although a critical composition region does not completely block access to the desired region, an infeasible region imposed by the reflux boundaries can prevent a composition trajectory from approaching the desired region. This infeasible region is determined by the lower and upper limitations of the internal reflux ratio calculated from the constraints on material balances, and these limitations are called reflux boundaries. To access the desired region, the internal reflux ratio should be less than the upper boundary or be larger than the lower boundary. To be more specific, if the internal reflux ratio of the composition trajectory has a value between the lower and the upper reflux boundaries, the composition trajectory rapidly goes to the $\overline{\mathrm{R}} 1-\overline{\mathrm{P} 1}$ binary edge in the Ent-projected region as the stage goes up to the reactive extractive section. 
An infeasible region confined by the reflux boundaries in the four-component system without an entrainer was derived previously. ${ }^{15,33}$ In this study, the concept of an infeasible region imposed by reflux boundaries is extended for the fivecomponent system and is derived as follows.

5.1. Formularize Two-Component-Projected Material Balances. A total material balance of the envelope in Figure 1 is given by

$$
V_{n+1}=L_{n}+D-E-A-\nu_{\mathrm{T}} \xi_{n}
$$

where $n$ is the number of stages counted from the top to the bottom and $\xi_{n}$ represents the accumulated reaction extent from the top to stage $n . \nu_{\mathrm{T}}$ is the sum of the stoichiometric coefficients of all components. For example, $\nu_{\mathrm{T}}$ is equal to zero for an isomolar reaction system as in eq 1 .

A component material balance gives

$$
V_{n+1} \mathbf{y}_{n+1}=L_{n} \mathbf{x}_{n}+D \mathbf{x}_{\mathrm{D}}-E \mathbf{x}_{\mathrm{E}}-A \mathbf{x}_{\mathrm{A}}-\boldsymbol{\nu} \xi_{n}
$$

where $\nu$ is a stoichiometric vector. For example $\nu$ is $[-1,-1,1$, $1,0]$ for R1, R2, P1, P2, and Ent in eq 1 .

Equations 5 and 6 can be rederived for the two-componentprojected system, and thus, the following material balance can be given

$$
\begin{aligned}
& \overline{\bar{V}}_{n+1}=\overline{\bar{L}}_{n}+\overline{\bar{D}}-\overline{\bar{E}}-\overline{\bar{A}} \\
& \overline{\bar{V}}_{n+1} \overline{\overline{\mathbf{y}}}_{n+1}=\overline{\bar{L}}_{n} \overline{\mathbf{x}}_{n}+\overline{\bar{D}} \overline{\overline{\mathbf{x}}}_{\mathrm{D}}-\overline{\bar{E}} \overline{\mathbf{x}}_{\mathrm{E}}-\overline{\bar{A}} \overline{\overline{\mathbf{x}}}_{\mathrm{A}}-\overline{\bar{\nu}} \xi_{n}
\end{aligned}
$$

where

$$
\begin{aligned}
& \overline{\bar{V}}_{n+1}=\left(1-y_{n+1, k 1}-y_{n+1, k 2}\right) V_{n+1} \\
& \overline{\bar{L}}_{n}=\left(1-x_{n, k 1}-x_{n, k 2}\right) L_{n} \\
& \overline{\bar{D}}=\left(1-x_{\mathrm{D}, k 1}-x_{\mathrm{D}, k 2}\right) D \\
& \overline{\bar{E}}=\left(1-x_{\mathrm{E}, k 1}-x_{\mathrm{E}, k 2}\right) E \\
& \overline{\bar{A}}=\left(1-x_{\mathrm{A}, k 1}-x_{\mathrm{A}, k 2}\right) A
\end{aligned}
$$

Here, $\overline{\bar{\nu}}$ is a double-projected stoichiometric vector and $k 1$ and $k 2$ represent projection components.

5.2. Find a Lower Reflux Boundary in the R1 and Ent Projection. As explained above, the approach of the composition trajectory to point $\overline{\overline{\mathrm{P} 1}}$ in the R1- and Entprojected plane implies the approach to the P1-R1-Ent ternary plane in the five-component system. To reach point $\overline{\overline{\mathrm{P} 1}}$ as the composition trajectory goes up in the reaction section, the vapor fraction of P1 of the lower stage should be smaller than that of the upper stage under the R1 and Ent projection. In other words, $\overline{\overline{\mathrm{y}}}_{n+1}$ should be farther away from the $\overline{\overline{\mathrm{P} 1}}$ point than $\overline{\mathbf{y}}_{n}$ in this plane. From this criterion, a lower reflux boundary can be calculated by assuming the extreme case of the pinch point $\left(\overline{\mathbf{y}}_{n}=\overline{\mathbf{y}}_{n+1}\right)$.

Because pure P1 is separated from the top of the column (D), pure R1 is supplied to the top of the reaction section (E), and pure Ent is supplied to the top stage of the column (A), it is clear that $x_{\mathrm{D}, \mathrm{R} 1}=0, x_{\mathrm{D}, \mathrm{Ent}}=0, x_{\mathrm{E}, \mathrm{R} 1}=1$, and $x_{\mathrm{A}, \mathrm{Ent}}=1$. Therefore, eq 8 is rearranged as follows in the R1 and Ent projection

$$
\overline{\bar{V}}_{n+1} \overline{\overline{\mathbf{y}}}_{n+1}+\overline{\overline{\boldsymbol{\nu}}} \xi_{n}=\left(1-x_{n, \mathrm{R} 1}-x_{n, \text { Ent }}\right) L_{n} \overline{\overline{\mathbf{x}}}_{n}+D \overline{\overline{\mathbf{x}}}_{\mathrm{D}}
$$

Equation 14 geometrically implies that the straight line from $\overline{\mathbf{y}}_{n+1}$ to $\overline{\overline{\boldsymbol{\nu}}}$ intersects with a straight line from $\overline{\mathbf{x}}_{n}$ to $\overline{\mathbf{x}}_{\mathrm{D}}$ at a singular point $(*)$ by the lever rule. ${ }^{15,33}$ When a pinch situation is assumed $\left(\overline{\overline{\mathbf{y}}}_{n+1}=\overline{\mathbf{y}}_{n}\right)$, the geometrical interpretation of eq 14 is given by Figure 5 .

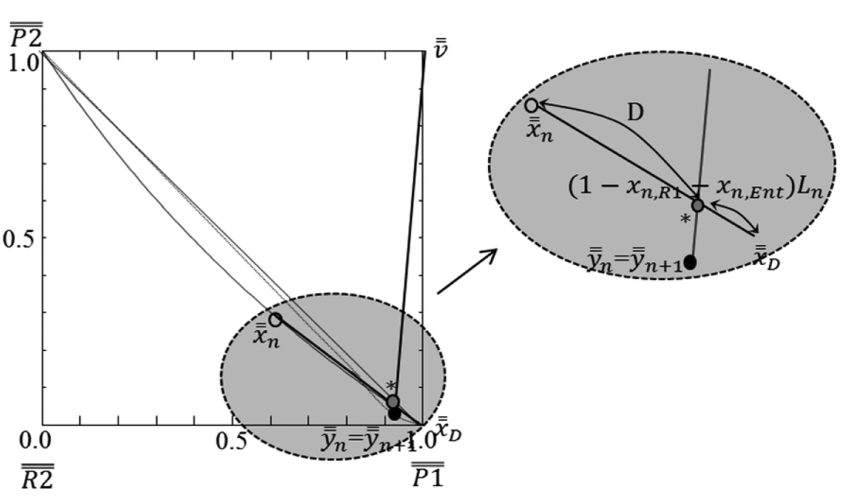

Figure 5. Lower reflux boundary in the R1 and Ent projection under the pinch-point assumption (white point, $\overline{\bar{x}}_{n}$; black point, $\overline{\mathbf{y}}_{n}=\overline{\overline{\mathbf{y}}}_{n+1}$; gray point, *).

The position of $\overline{\bar{y}}_{n+1}$ is determined by the position of $*$, and the position of $*$ also depends on the length ratio of the segments $\overline{\overline{\mathbf{x}}}_{n}{ }^{*}$ to $\overline{\overline{\mathbf{x}}}_{\mathrm{D}}{ }^{*}$ by the lever rule. Therefore, it is clear that the position of $\overline{\overline{\mathbf{y}}}_{n+1}$ is determined by the length ratio of $\overline{\overline{\mathbf{x}}}_{n}{ }^{*}$ to $\overline{\overline{\mathbf{x}}}_{\mathrm{D}}{ }^{*}$. From the lever rule of eq 14 , the length ratio of $\overline{\overline{\mathbf{x}}}_{\mathrm{D}}{ }^{*}$ to $\overline{\overline{\mathbf{x}}}_{n}{ }^{*}$, which is geometrically measured in Figure 5 is equal to (1 $\left.-x_{n, \mathrm{R} 1}-x_{n, \mathrm{Ent}}\right) L_{n} / D$. Because $x_{n, \mathrm{R} 1}$ and $x_{n, \text { Ent }}$ are known at an arbitrary stage on the reaction equilibrium, the internal reflux ratio $L_{n} / D$ is easily calculated from the measured length ratio and known liquid compositions. However, because we assumed the pinch-point situation, this ratio is not equal to the real internal reflux ratio. To distinguish the geometrically measured internal reflux ratio under the pinch-point assumption from the real internal reflux ratio, the suffix $G$ is attached to the geometrically measured internal reflux ratio. In other words, the geometrically measured length ratio of $\overline{\overline{\mathbf{x}}}_{\mathbf{D}}{ }^{*}$ to $\overline{\overline{\mathbf{x}}}_{n}{ }^{*}$ divided by (1 $\left.-x_{n, \mathrm{R} 1}-x_{n, \mathrm{Ent}}\right)$ is written as $\left(L_{n} / D\right)_{\mathrm{G}}$.

As previously mentioned, to reach point $\overline{\overline{\mathrm{P} 1}}$ in the R1- and Ent-projected plane, point $\overline{\overline{\mathbf{y}}}_{n+1}$ should be farther from point $\overline{\overline{\mathrm{P} 1}}$ than point $\overline{\mathbf{y}}_{n}$ placed under the pinch assumption. Then, the combined point $(*)$ moves closer to $\overline{\mathbf{x}}_{n}$, and the ratio $\left(1-x_{n, \mathrm{R} 1}\right.$ $\left.-x_{n, \text { Ent }}\right) L_{n} / D$ in Figure 5 increases. Therefore, the real internal reflux ratio $L_{n} / D$ should be larger than the geometrically measured internal reflux ratio $\left(L_{n} / D\right)_{\mathrm{G}}$, and thus, $\left(L_{n} / D\right)_{\mathrm{G}}$ is called the lower boundary of the internal reflux ratio.

5.3. Find an Upper Reflux Boundary in the P1 and Ent Projection. In the same manner as for the R1 and P1 projection case, to reach point $\overline{\overline{\mathrm{R}} 1}$ in the P1- and Ent-projected plane, the position of $\overline{\bar{y}}_{n+1}$ should be farther from point $\overline{\overline{\mathrm{R} 1}}$ than that of $\overline{\mathbf{y}}_{n}$. From this criterion, an upper reflux boundary can be calculated by assuming the extreme case of the pinch point $\left(\overline{\overline{\mathbf{y}}}_{n+1}=\overline{\overline{\mathbf{y}}}_{n}\right)$.

Because pure P1 is recovered from the top of the column (D), pure R1 is supplied to the top stage of the reaction section (E), and pure Ent is supplied to the top stage of the column (A), it is clear that $x_{\mathrm{D}, \mathrm{P} 1}=1, x_{\mathrm{E}, \mathrm{P} 1}=0, x_{\mathrm{E}, \mathrm{Ent}}=0$, and $x_{\mathrm{E}, \mathrm{Ent}}=1$. Therefore, eq 8 can be rearranged as follows 


$$
\left(1-y_{n+1, \mathrm{P1}}-y_{n+1, \mathrm{Ent}}\right) V_{n+1} \overline{\overline{\mathbf{y}}}_{n+1}+E \overline{\overline{\mathbf{x}}}_{\mathrm{E}}=\overline{\bar{L}}_{n} \overline{\overline{\mathbf{x}}}_{n}-\overline{\overline{\boldsymbol{\nu}}} \xi_{n}
$$

When a pinch situation is assumed $\left(\overline{\overline{\mathbf{y}}}_{n+1}=\overline{\overline{\mathbf{y}}}_{n}\right)$, eq 15 is also visualized at the P1- and Ent-projected ternary composition plane by the lever rule shown in Figure 6.

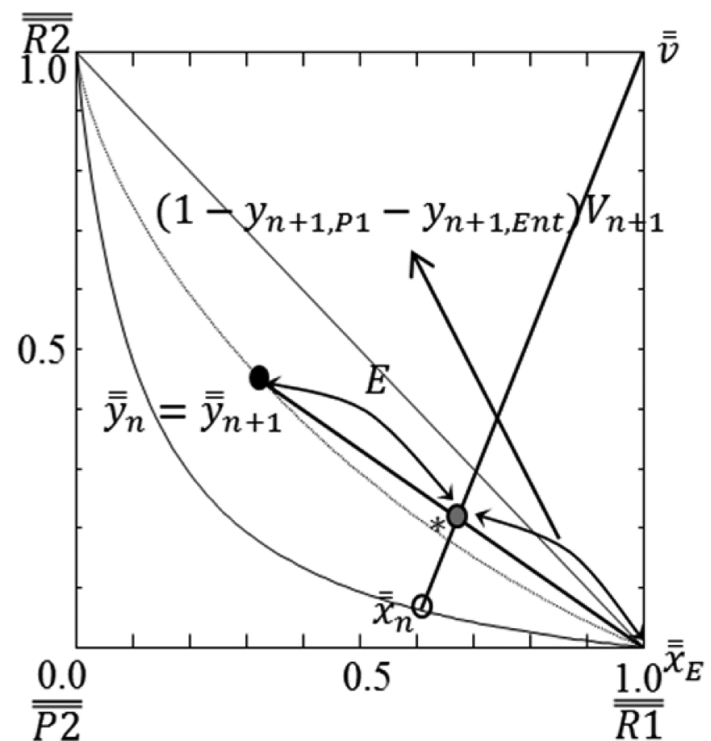

Figure 6. Upper reflux boundary in the P1 and Ent projection under the pinch-point assumption (white point, $\overline{\mathbf{x}}_{n}$; black point, $\overline{\overline{\mathbf{y}}}_{n}=\overline{\overline{\mathbf{y}}}_{n+1}$; gray point, $*)$.

The position of $\overline{\overline{\mathbf{y}}}_{n+1}$ is determined by the length ratio of $\overline{\overline{\mathbf{x}}}_{\mathrm{E}}{ }^{*}$ to $\overline{\overline{\mathbf{y}}}_{n+1}{ }^{*}$. This geometrically measured ratio in Figure 6 is equal to the ratio $\left(1-y_{n+1, \mathrm{P} 1}-y_{n+1, \mathrm{Ent}}\right) V_{n+1} / E$ by the lever rule. Because $y_{n+1, \mathrm{P} 1}\left(=y_{n, \mathrm{Ent}}\right)$ and $y_{n+1, \mathrm{Ent}}\left(=y_{n, \text { Ent }}\right)$ at an arbitrary stage are known by phase equilibria, $V_{n+1} / E$ is calculated from the geometrically measured length ratio and known vapor compositions. Likewise in the R1 and Ent projection case, this ratio under the pinch-point assumption is written as $\left(V_{n+1} / E\right)_{\mathrm{G}}$ to distinguish it from the real ratio $V_{n+1} / E$. As can be seen in Figure 6, to place $\overline{\overline{\mathbf{y}}}_{n+1}$ farther from point $\overline{\overline{\mathrm{R}} 1}$ than $\overline{\overline{\mathbf{y}}}_{n}$, the real ratio $V_{n+1} / E$ should be smaller than the geometrically measured ratio $\left(V_{n+1} / E\right)_{\mathrm{G}}$.

Then, we use an overall material balance to relate these two (upper and lower) boundaries to the internal reflux ratio at an arbitrary stage. To do this, the overall material balance equation (eq 3) is rearranged as follows (isomolar reaction, $\nu_{\mathrm{T}}=0$ )

$$
V_{n+1} / E=\left(L_{n} / D\right)(D / E)+D / E-A / E-1
$$

Because the amount of makeup entrainer $(A)$ is negligible compared with $E, A / E$ is disregarded. Moreover, when the full reaction conversion and pure product recovery are achieved with the stoichiometric feed, $D / E$ is equal to 1 . As eq 16 is substituted into the upper boundary condition $V_{n+1} / E<\left(V_{n+1} /\right.$ $E)_{\mathrm{G}}$, the following equation is derived

$$
L_{n} / D<\left(V_{n+1} / E\right)_{\mathrm{G}}
$$

Therefore, $\left(V_{n+1} / E\right)_{\mathrm{G}}$ is called an upper reflux boundary. ${ }^{33}$

For the R1 and P1 projection, a meaningful relationship between the upper and lower internal reflux boundaries is not derived (refer to Appendix A). Therefore, from the two projections of R1-Ent and P1-Ent, one can geometrically determine the upper and lower boundaries of internal reflux ratios. Through the derivations described above, it is clear that the composition trajectory can approach the desired R1-P1Ent plane when the internal reflux ratio of the composition trajectory is larger than its lower boundary or smaller than its upper boundary. On the contrary, because the region where the lower boundary of internal reflux ratio $\left[\left(L_{n} / D\right)_{\mathrm{G}}\right]$ is larger than its upper boundary $\left[\left(V_{n+1} / E\right)_{\mathrm{G}}\right]$ has potential to prevent the composition trajectory from approaching the desired region under the condition that its internal reflux ratios are between boundaries, this region is called the infeasible region constrained by the reflux boundaries.

To evaluate the feasibility of IPA reactive extractive distillation, the infeasible regions imposed by the reflux boundaries with $\mathrm{Chl}$ and Hexane are plotted in Figures 7 and

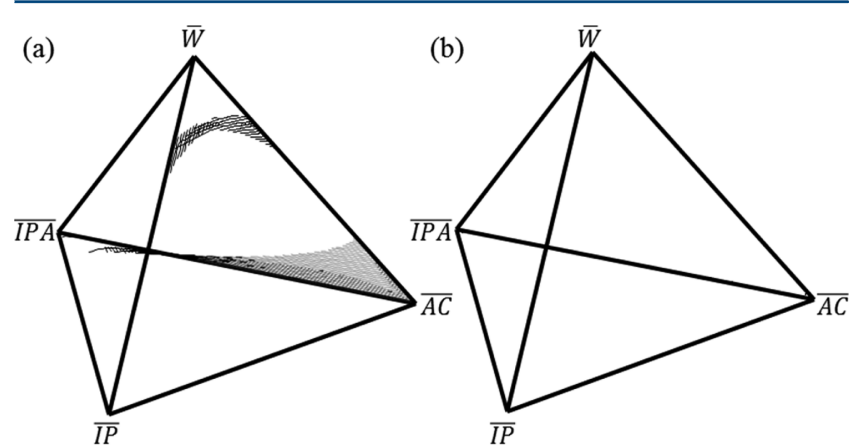

Figure 7. Infeasible shaded region confined by reflux boundaries for the IPA production system with Chl: (a) $x_{\mathrm{Chl}}=0.2$, (b) $x_{\mathrm{Chl}}=0.4$.

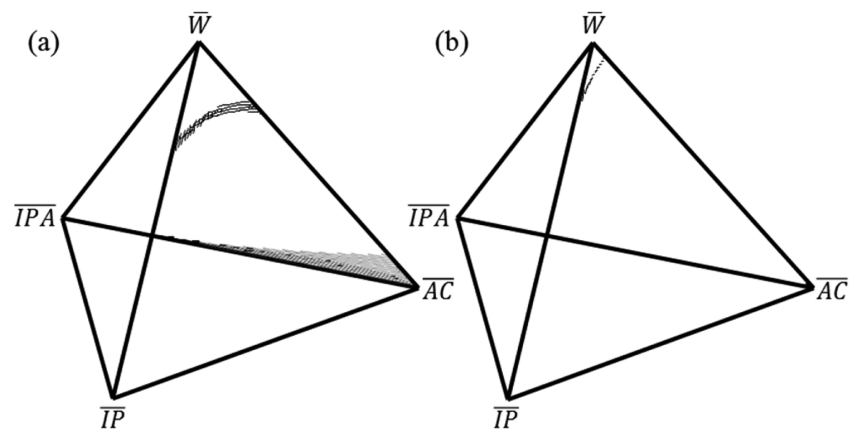

Figure 8. Infeasible shaded region confined by reflux boundaries for the IPA production system with Hexane: (a) $x_{\text {Hexane }}=0.2$, (b) $x_{\text {Hexane }}=$ 0.4 .

8 , respectively. The infeasible regions are decreased in the IPA production system as the molar fraction of liquid entrainer in the quinary mixture is increased from 0.2 to 0.4 . Therefore, the full reaction conversion and high product purities can be obtained in the IPA system by introducing one of these two entrainers.

\section{APPLICATION TO ETHYL ACETATE PRODUCTION SYSTEMS}

One can apply the concepts of the critical composition region and reflux boundaries for evaluating the feasibilities of several reactive extractive systems. ${ }^{18-21}$ However, the ethyl acetate (EA) production system was selected because its feasibility is restricted by the reflux boundaries without any entrainer. The 
complete conversion of the ethyl acetate reaction cannot be achieved through double-feed reactive distillation because of the infeasible region confined by the reflux boundaries. ${ }^{15}$ The reaction is

$$
\mathrm{AC}+\mathrm{EtOH} \leftrightarrow \mathrm{EA}+\mathrm{W}
$$

where $\mathrm{EtOH}, \mathrm{AC}$, and $\mathrm{W}$ represent ethanol, acetic acid, and water, respectively. From the relative volatilities, $\mathrm{AC}, \mathrm{EtOH}$, $\mathrm{EA}$, and $\mathrm{W}$ correspond to $\mathrm{R} 1, \mathrm{R} 2, \mathrm{P} 1$, and $\mathrm{P} 2$, respectively. Although the critical composition region of this system does not completely cover the desired AC-EA binary edge as shown in Figure 9a, the infeasible region confined by the reflux

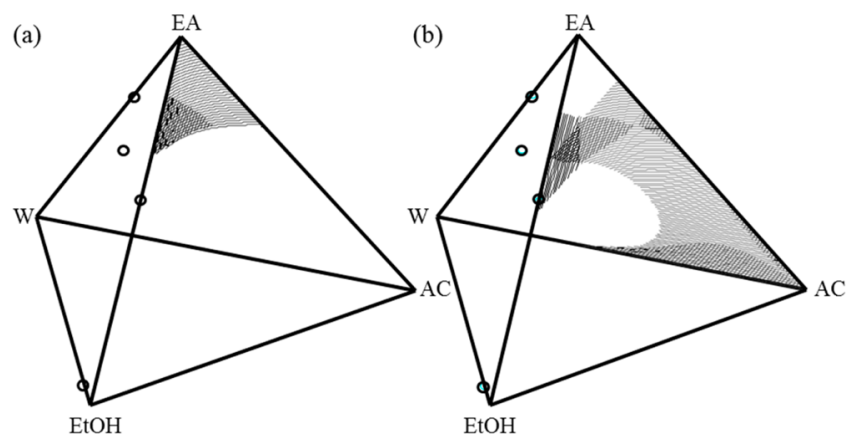

Figure 9. (a) Critical composition region and (b) infeasible region confined by reflux boundaries of the EA system without any entrainer. Open circles are azeotropes of the EA system.

boundaries shades most of the AC-EA binary edge in Figure 9b. In other words, even if thermodynamic constraints can be avoided, the infeasible region cannot be eliminated through reactive distillation without an entrainer.

To eliminate the infeasible region and achieve full reaction conversion, an entrainer of dichloromethane (Dichl) or $n$ pentane (Pentane) is introduced for the production of pure EA. As for the IPA production system with the entrainer, the entrainer increases the relative volatility of $\mathrm{W}$ by forming a minimum heterogeneous azeotrope with $\mathrm{W}$, and this minimum heterogeneous azeotrope is separated from the top of the column and decanted to almost-pure water in the fivecomponent system. Thus, $\mathrm{P} 1$ is changed from $\mathrm{EA}$ to $\mathrm{W}$ in the five-component system. To calculate the critical composition region and the reflux-bounded infeasible region, reaction equilibrium data are used from previous research. ${ }^{36,37}$ NRTL binary parameters and calculated azeotropes in the EA quinary systems with entrainers were acquired from Aspen Plus and are included in Tables S4-S6 (Supporting Information).

As for the IPA system with the entrainer, there is no critical composition region in the EA system with the entrainer when the constant fractions of the entrainer are from 0.01 to 0.99 (Figure 10). The infeasible regions imposed by the reflux boundaries are calculated and plotted for the entrainerprojected system in Figures 11 and 12. The infeasible region is dramatically decreased as the molar fraction of liquid entrainer in the quinary mixture is increased 0.2 to 0.6 . Therefore, we can conclude that full reaction conversion and high-purity products can be achieved in the EA production system by introducing Dichl or Pentane as an entrainer.

\section{TRAY-BY-TRAY CALCULATIONS}

To validate the feasibility evaluation described above, rigorous tray-by-tray calculations were performed on the basis of

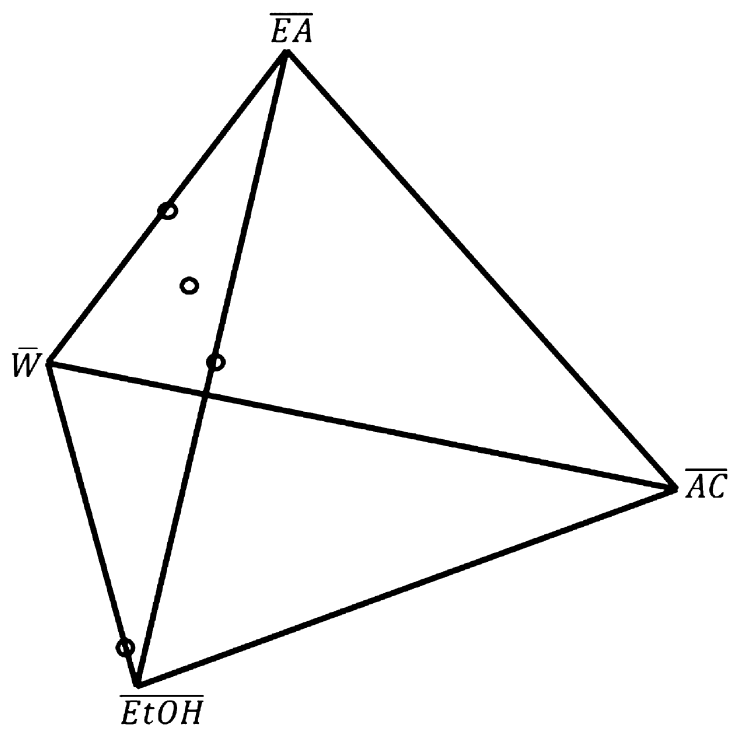

Figure 10. Null of the critical composition region of the EA system with dichloromethane and $n$-pentane. Open circles are azeotropes of the EA system $\left(x_{\text {Ent }}=0.01-0.99\right)$.

material and energy balances. The calculated reflux boundaries as well as the real internal reflux ratio of the composition trajectory were traced in both the IPA and EA production systems with the four entrainers as the composition trajectory goes up to the top of the reactive extractive section. As can be seen from the tray-by-tray calculations and calculated internal reflux ratios in Figures 13-16, the composition trajectories could approach the desired binary edge when their internal reflux ratios were larger than their lower boundaries or smaller than their upper boundaries. In Figure 13, although the internal reflux ratios of stages 8-10 are larger than their upper reflux boundaries, they are also larger than their lower reflux boundaries. Therefore, the composition trajectory can approach the $\overline{\mathrm{AC}}-\overline{\mathrm{W}}$ binary edge on these stages. Likewise, the internal reflux ratios of lower stages in Figures 14 and 16 (stages 8-10 in Figure 14 and stages $18-20$ in Figure 16) are smaller than their lower reflux boundaries. However, because they are still lower than their upper reflux boundaries, the composition trajectory can approach the $\overline{\mathrm{AC}}-\overline{\mathrm{W}}$ binary edge on these stages. After reaching the $\overline{\mathrm{AC}}-\overline{\mathrm{W}}$ binary edge (AC-W-Ent ternary plane in the original composition space) on the upper feed stage, AC is separated from the W-Ent heterogeneous azeotrope by the nonreactive rectifying section, and the minimum-boiling azeotrope is decanted to pure water and an Ent-rich phase.

\section{SIMULATION RESULTS}

The main results of the Aspen Plus simulations are reported in Table S7 (Supporting Information). Almost 100\% conversion is achieved with the stoichiometric feed of reactants. The total number of stages, the number of reactive stages, and the location of the reaction section were selected on the basis of previous works. ${ }^{16-18,21}$ The total number of stages was $26-30$, and the number of reactive stages was 10-20 (numbers of reactive/total stages: general fatty acid ester, $15 / 30 ;{ }^{16,17}$ butyl acetate, $11 / 28{ }^{21}$ butyl cellosolve acetate, $20 / 26-30^{18}$ ). Because a high number of stages is needed for a system that has a high molar fraction of entrainer in the minimum heterogeneous azeotrope, a lower number of stages was used 

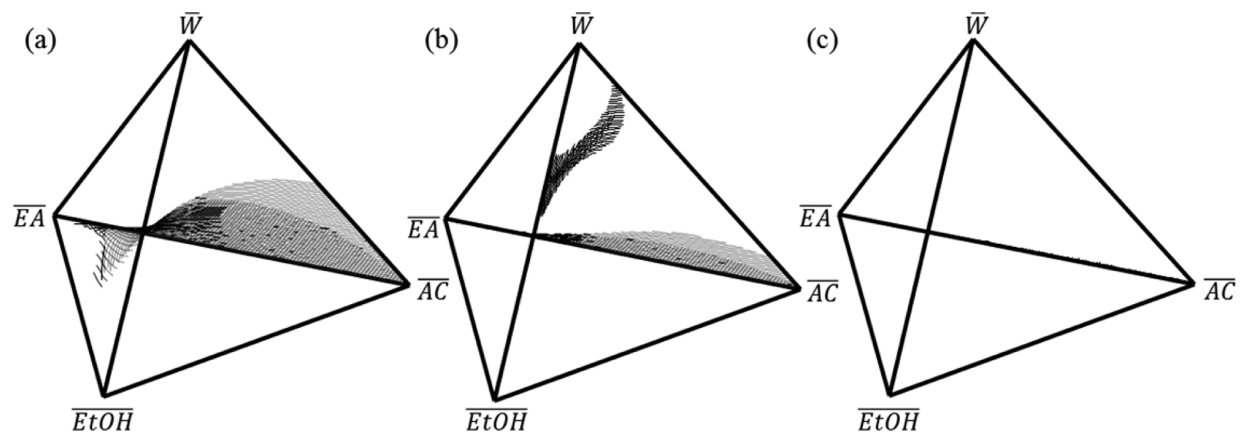

Figure 11. Infeasible region confined by the reflux boundaries of the EA production system with Dichl: (a) $x_{\text {Dichl }}=0.2$, (b) $x_{\text {Dichl }}=0.4$, (c) $x_{\text {DChl }}=$ 0.6 .
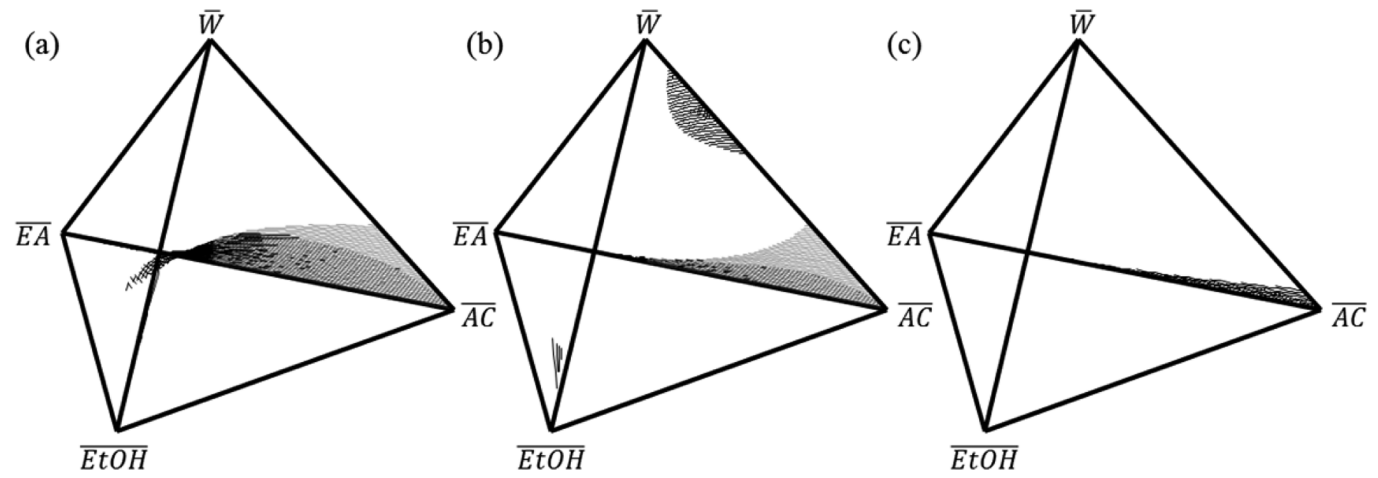

Figure 12. Infeasible region confined by the reflux boundaries of the EA production system with Pentane: (a) $x_{\text {Pentane }}=0.2$, (b) $x_{\text {Pentane }}=0.4$, (c) $x_{\text {Pentane }}=0.6$.

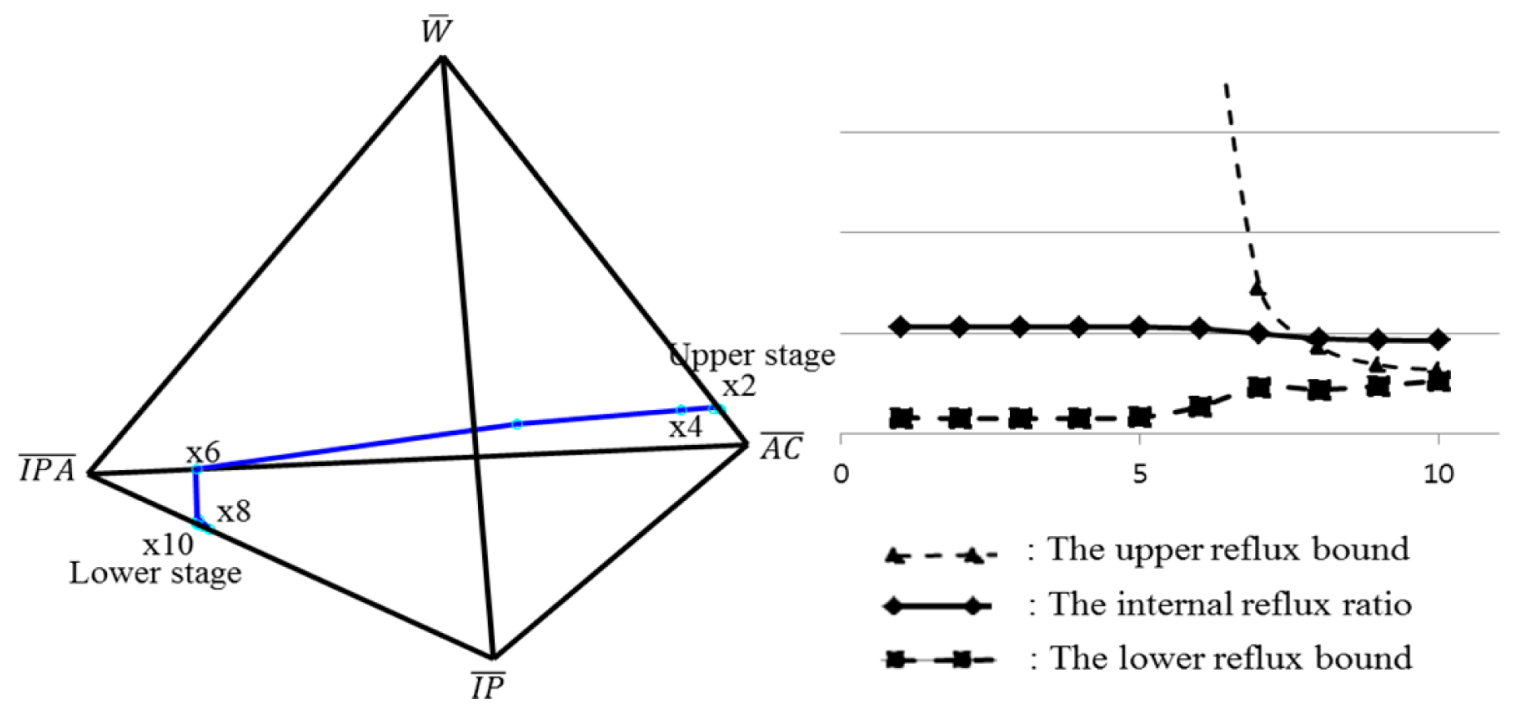

Figure 13. Tray-by-tray calculations and reflux ratios of the IPA production system with Chl.

for the IPA production system than for the EA production system. Therefore, $11 / 30$ and $21 / 40$ reactive/total stages were used for the IPA and EA production systems, respectively. However, there is no general rule for the location of the reaction section (fatty acid ester, $15-29 ;{ }^{16,17}$ butyl acetate, $8-$ $18 ;^{21}$ butyl cellosolve acetate, $5-24^{18}$ ). Because the objective of this study was a feasibility evaluation by the graphical method, not an optimization of the process, the reaction sections for both systems were located at the middle of the column to avoid a shortage in the number of nonreactive rectifying or stripping stages. Because a small amount of Ent is dissolved in product streams, it should be provided to compensate for the loss. As can be seen from Table S7 (Supporting Information), the purities of the products in the IPA-Hexane system are lower than those of the products in the other systems. This is because the reaction extent is smaller in the IPA-Hexane system than in the other systems. In Figures 13, 15, and 16, each composition trajectory reaches the $\overline{\mathrm{AC}}-\overline{\mathrm{W}}$ binary edge at stages 3,14 , and 15 below the top stage of the reaction section. However, that of IPA-Hexane system (Figure 14) is still away from that binary edge at stage 2 . It barely approaches the $\overline{\mathrm{AC}}-$ $\bar{W}$ binary edge at the top stage of the reaction section. Therefore, we note that the number of reactive stages might 


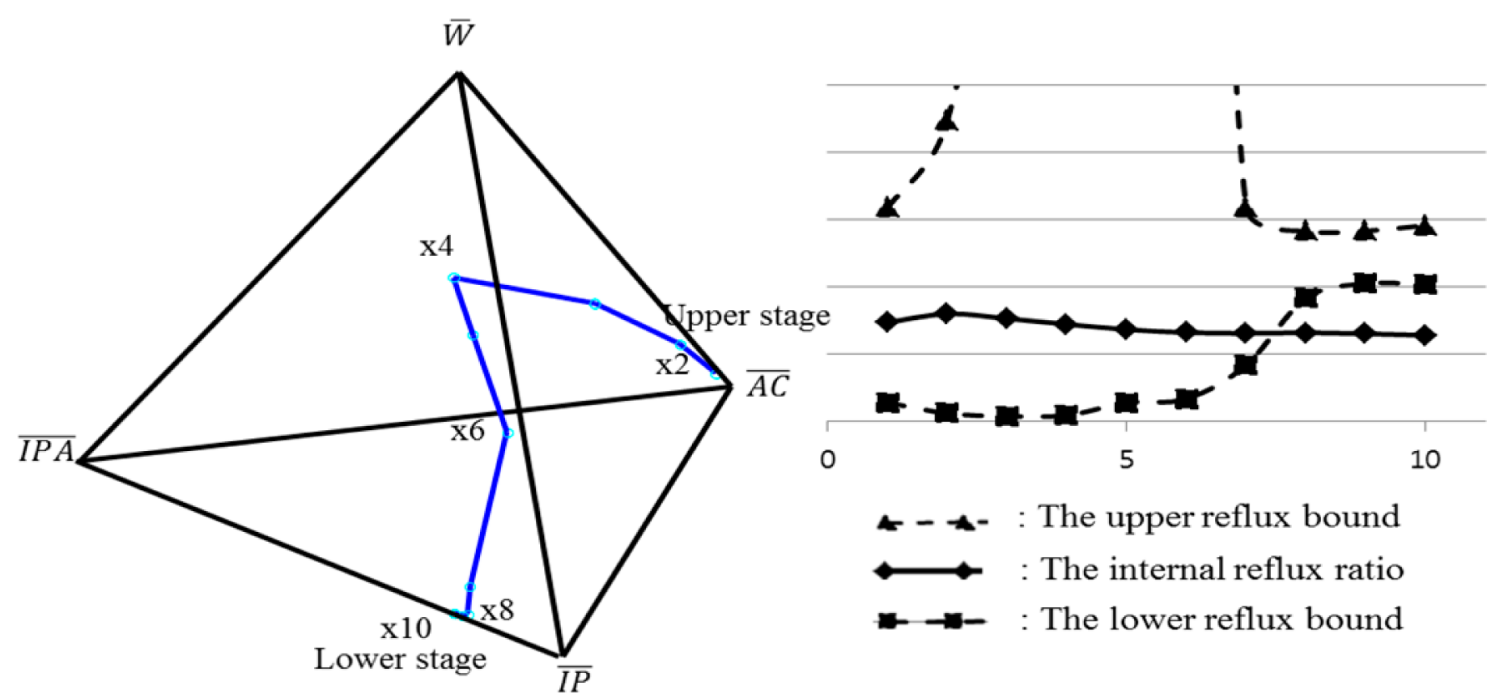

Figure 14. Tray-by-tray calculations and reflux ratios of the IPA production system with Hexane.
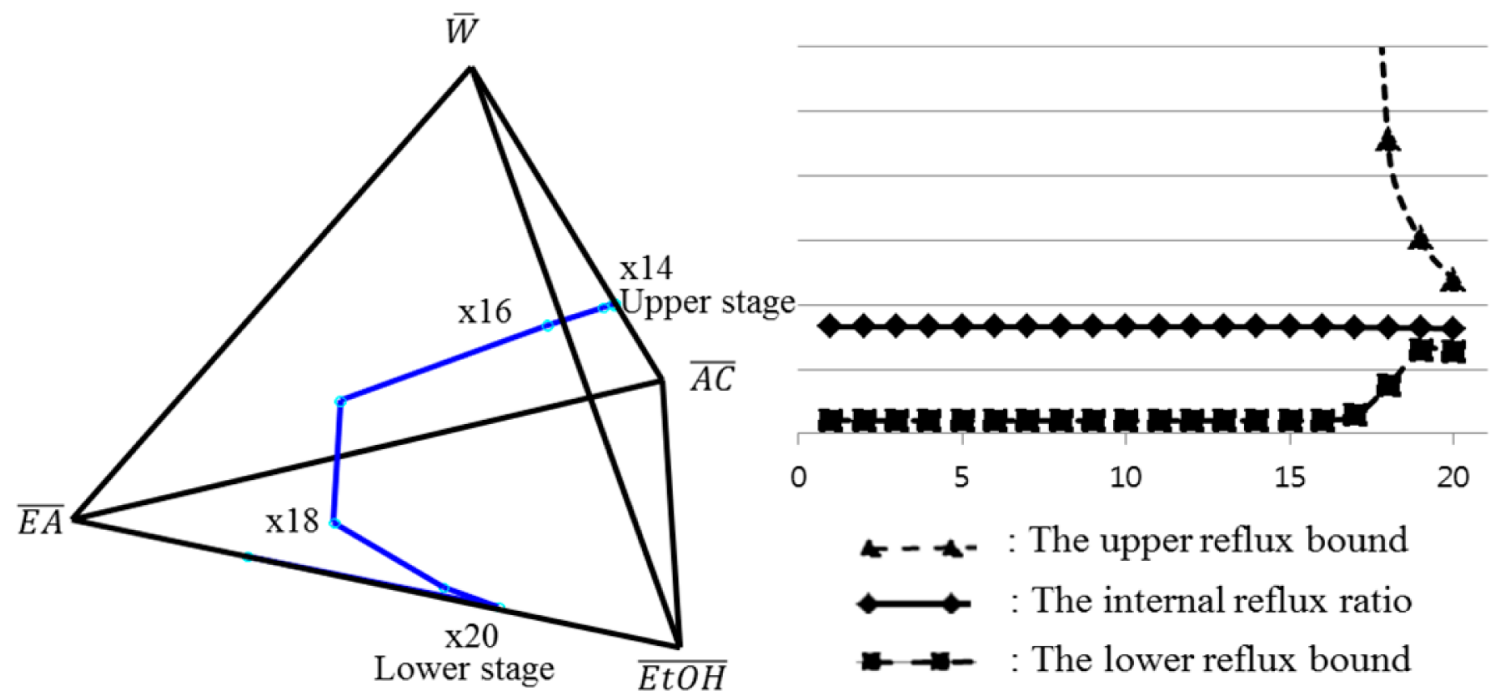

Figure 15. Tray-by-tray calculations and reflux ratios of the EA production system with Dichl.
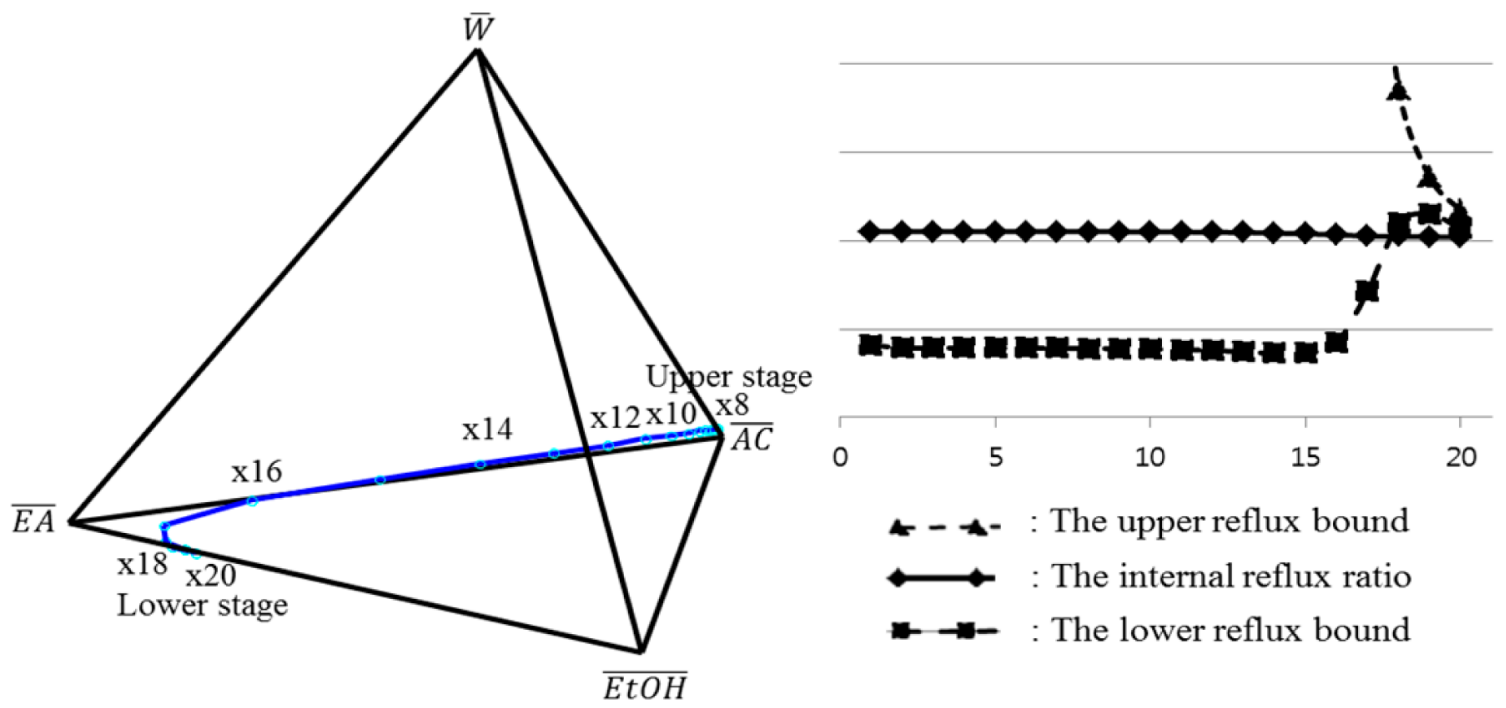

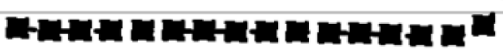

0

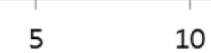

10

15

20

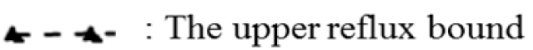

$\leftrightarrow \quad$ : The internal reflux ratio

- $\rightarrow-\quad$ : The lower reflux bound

Figure 16. Tray-by-tray calculations and reflux ratios of the EA production system with Pentane. 
not be high enough to achieve full reaction conversion and the recovery of highly pure products in the IPA-Hexane system. Additional reactive stages or nonreactive separation columns might be needed.

\section{CONCLUSIONS}

On the basis of an understanding of reaction and phase equilibria, a reliable feasibility evaluation method for quinary reactive extractive distillation is proposed. The concepts of the critical composition region and the infeasible region confined by the reflux boundaries are derived with the introduction of an external heterogeneous entrainer for the purpose of achieving full reaction conversion and pure product recovery. When compared with the four-component system without an entrainer, the critical composition region where thermodynamic constraints prevent the composition trajectory from approaching the desired region is dramatically decreased by introducing the proper entrainer into the complex azeotropic reacting system. This is because the desired region is enlarged from the binary edge in the quaternary system to the ternary plane in the quinary system. The infeasible region confined by the reflux boundaries calculated from the material balance constraints is also decreased as the fraction of entrainer increases. Because both the critical composition region and the reflux-bounded infeasible region do not completely shade the desired ternary plane by having a permissible range of internal reflux ratios near the desired ternary plane, the EA and IPA production systems can achieve full reaction conversion and produce pure products through reactive extractive distillation. Rigorous tray-by-tray calculations and Aspen Plus simulations confirmed the validity of feasibility evaluation procedures with various entrainers. From the concepts of the critical composition region and the reflux-bounded infeasible region, the feasibility of reactive extractive distillation can be easily evaluated with simple calculations on the basis of phase and reaction equilibria before detailed simulations and experiments are performed.

\section{APPENDIX A}

In the $\mathrm{R} 1$ and $\mathrm{P} 1$ projection, it is also clear that $x_{\mathrm{D}, \mathrm{P} 1}=1$ and $x_{\mathrm{E}, \mathrm{R} 1}=1$. Therefore, eqs 7 and 8 can be rearranged as follows

$$
\begin{aligned}
& \overline{\bar{V}}_{n+1}=\overline{\bar{L}}_{n}-A \\
& A \overline{\mathbf{x}}_{\mathrm{A}}+\xi_{n}\left(\overline{\overline{\mathbf{C}}}_{\mathrm{P}}-\overline{\overline{\mathbf{C}}}_{\mathrm{R}}\right)=\overline{\bar{L}}_{n} \overline{\mathbf{x}}_{n}+\overline{\bar{V}}_{n+1} \overline{\mathbf{y}}_{n+1}
\end{aligned}
$$

Because $\overline{\bar{\nu}}=[-1,1,0]$ for R2, P2, and Ent, respectively, and thus the sum of each component is zero, it cannot be visualized at the ternary component plane. ${ }^{38}$ Therefore, the decomposition of $\overline{\bar{\nu}}^{39}$ into $\overline{\mathrm{C}}_{\mathrm{P}}=[0,1,0]$ and $\overline{\overline{\mathrm{C}}}_{\mathrm{R}}=[1,0,0]$ is used instead of $\overline{\bar{\nu}}$ at the $\mathrm{R} 1$ and $\mathrm{P} 1$ projection plane $\left(\overline{\bar{\nu}}=\overline{\overline{\mathrm{C}}}_{\mathrm{P}}-\overline{\overline{\mathrm{C}}}_{\mathrm{R}}\right)$.

Because the amount of makeup entrainer $(A)$ is negligible compared with $\overline{\bar{L}}_{n}$, we can divide eq A.1 by $\overline{\bar{L}}_{n}$ and substitute the result into eq A. 2 to derive the equation

$$
\left(\frac{\xi_{n}}{\overline{\bar{L}}_{n}}\right)\left(\mathbf{C}_{\mathrm{P}}-\mathbf{C}_{\mathrm{R}}\right)=\overline{\mathbf{x}}_{n}+\overline{\overline{\mathbf{y}}}_{n+\mathbf{1}}
$$

From eq A.3, one can see that the straight line from $C_{P}$ to $C_{R}$ is parallel to the straight line from $\overline{\overline{\mathbf{x}}}_{n}$ to $\overline{\overline{\mathbf{y}}}_{n+1}$. Unlike the R1/Ent and $P 1 /$ Ent projections, because $C_{P}$ and $C_{R}$ are fixed, the position of $\overline{\overline{\mathbf{y}}}_{n+1}$ is affected only by the position of $\overline{\mathbf{x}}_{n}$, not by a reflux ratio. Therefore, any reflux constraints are derived from the $\mathrm{R} 1$ and $\mathrm{P} 1$ projection.

\section{ASSOCIATED CONTENT}

\section{Supporting Information}

Detailed NRTL parameters, calculated azeotropes, and Aspen Plus simulation results. This material is available free of charge via the Internet at http://pubs.acs.org/.

\section{AUTHOR INFORMATION}

\section{Corresponding Author}

*Tel.: +82-42-350-3940. Fax: +82-42-350-3910. E-mail: jaewlee@kaist.ac.kr. Address: Department of Chemical and Biomolecular Engineering, Korea Advanced Institute of Science and Technology (KAIST), 291 Daehak-ro, Yuseong-gu, Daejeon 305-701, Republic of Korea.

\section{Notes}

The authors declare no competing financial interest.

\section{ACKNOWLEDGMENTS}

This work was supported by both the Midcareer Researcher Program through an NRF grant (2014R1A2A2A01007076) and the Advanced Biomass R\&D Center $(\mathrm{ABC})$ as the Global Frontier Project funded by the Ministry of Science, ICT, and Future Planning.

\section{NOMENCLATURE}

$A=$ molar flow rate of an accommodated entrainer

$\bar{A}=$ molar flow rate of an accommodated entrainer in a projected space

$\bar{A}=$ molar flow rate of an accommodated entrainer in a double-projected space

$D=$ molar flow rate of a distillate

$\bar{D}=$ molar flow rate of a distillate in a projected space

$\overline{\bar{D}}=$ molar flow rate of a distillate in a double-projected space

$E=$ molar flow rate of an upper feed

$\bar{E}=$ molar flow rate of an upper feed in a projected space

$\overline{\bar{E}}=$ molar flow rate of an upper feed in a double-projected space

$K_{\text {eq }}=$ reaction equilibrium constant

$L_{n}=$ molar flow rate of a liquid leaving stage $n$

$\bar{L}_{n}=$ molar flow rate of a liquid leaving stage $n$ in a projected space

$\overline{\bar{L}}_{n}=$ molar flow rate of a liquid leaving stage $n$ in a doubleprojected space

$\left(L_{n} / D\right)_{\mathrm{G}}=$ lower internal reflux boundary

$V_{n}=$ molar flow rate of a vapor leaving stage $n$

$\bar{V}_{n}=$ molar flow rate of a vapor leaving stage $n$ in a projected space

$\bar{V}_{n}=$ molar flow rate of a vapor leaving stage $n$ in a doubleprojected space

$\left(V_{n+1} / E\right)_{\mathrm{G}}=$ upper internal reflux boundary

$\mathbf{x}_{\mathrm{A}}=$ molar composition vector of an accommodated entrainer

$\overline{\mathbf{x}}_{\mathrm{A}}=$ molar composition vector of an accommodated entrainer in a projected space

$\overline{\mathbf{x}}_{\mathrm{A}}=$ molar composition vector of an accommodated entrainer in a double-projected space

$\mathbf{x}_{\mathrm{D}}=$ molar composition vector of a distillate

$\overline{\mathbf{x}}_{\mathrm{D}}=$ molar composition vector of a distillate in a projected space

$\overline{\overline{\mathbf{x}}}_{\mathrm{D}}=$ molar composition vector of a distillate in a doubleprojected space

$\mathbf{x}_{\mathrm{E}}=$ molar composition vector of an upper feed 
$\overline{\mathbf{x}}_{\mathrm{E}}=$ molar composition vector of an upper feed in a projected space

$\overline{\overline{\mathbf{x}}}_{\mathrm{E}}=$ molar composition vector of an upper feed in a doubleprojected space

$\mathbf{x}_{n}=$ molar composition vector of a liquid leaving stage $n$

$\overline{\mathbf{x}}_{n}=$ molar composition vector of a liquid leaving stage $n$ in a projected space

$\overline{\overline{\mathbf{x}}}_{n}=$ molar composition vector of a liquid leaving stage $n$ in a double-projected space

$x_{n, \text { comp }}=$ liquid molar composition of component comp on stage $n$

$\bar{x}_{n, k, \text { comp }}=$ liquid molar composition of component comp on stage $n$ in a component- $k$-projected space

$\overline{\mathbf{x}}_{n,(k 1, k 2), \text { comp }}=$ liquid molar composition of component comp on stage $n$ in a components $k 1$ and $k 2$ double-projected space

$\mathbf{y}_{n}=$ molar composition vector of a vapor leaving stage $n$

$\overline{\mathbf{y}}_{n}=$ molar composition vector of a vapor leaving stage $n$ in a projected space

$\overline{\overline{\mathbf{y}}}_{n}=$ molar composition vector of a vapor leaving stage $n$ in a double-projected space

$y_{n, \text { comp }}=$ vapor molar composition of component comp on stage $n$

$\bar{y}_{n, k, \text { comp }}=$ vapor molar composition of component comp on stage $n$ in a component- $k$-projected space

$\overline{\bar{y}}_{n,(k 1, k 2), \text { comp }}=$ vapor molar composition of component comp on stage $n$ in a component $k 1$ and $k 2$ double-projected space

\section{Greek Letters}

$\nu=$ stoichiometric coefficient vector

$\bar{\nu}=$ stoichiometric coefficient vector in a projected space

$\overline{\bar{\nu}}=$ stoichiometric coefficient vector in a double-projected space

$\nu_{\mathrm{T}}=$ sum of stoichiometric coefficients

$\xi_{n}=$ accumulated molar reaction extent from the top to stage

\section{Abbreviations}

$\mathrm{AC}=$ acetic acid

$\mathrm{Chl}=$ chloroform

comp $=$ component vector

$\overline{\mathrm{comp}}=$ component vector in a projected space

$\overline{\overline{\operatorname{comp}}}=$ component vector in a double-projected space

Dichl $=$ dichloromethane

$\mathrm{EA}=$ ethyl acetate

Ent $=$ entrainer

$\mathrm{EtOH}=$ ethyl alcohol

Hexane $=n$-hexane

IP = isopropyl alcohol

IPA = isopropyl acetate

Pentane $=n$-pentane

$\mathrm{W}=$ water

\section{REFERENCES}

(1) Taylor, R.; Krishna, R. Modelling reactive distillation. Chem. Eng. Sci. 2000, 55, 5183.

(2) Malone, M. F.; Doherty, M. F. Reactive distillation. Ind. Eng. Chem. Res. 2000, 39, 3953.

(3) Tuchlenski, A.; Beckmann, A.; Reusch, D.; Dussel, R.; Weidlich, U. Reactive distillation-Industrial applications, process design \& scale-up. Chem. Eng. Sci. 2001, 56, 387.

(4) Sundmacher, K.; Kienle, A. Reactive Distillation: Status and Future Directions; Wiley-VCH: Weinheim, Germany, 2002.

(5) Harmsen, G. J. Reactive distillation: The front-runner of industrial process intensification a full review of commercial application, research, scale-up, design and operation. Chem. Eng. Process. 2007, 46, 774.

(6) Lee, J. W.; Hauan, S.; Westerberg, A. W. Graphical methods for reaction distribution in a reactive distillation column. AIChE J. 2000, 46, 1218.

(7) Lee, J. W.; Hauan, S.; Westerberg, A. W. Circumventing an azeotrope in reactive distillation. Ind. Eng. Chem. Res. 2000, 39, 1061.

(8) Guo, Z.; Ghufran, M.; Lee, J. W. Feasible products in batch reactive distillation. AIChE J. 2003, 49, 3161.

(9) Guo, Z.; Lee, J. W. Feasible products in batch reactive extractive distillation. AIChE J. 2004, 50, 1484.

(10) Agreda, V. H.; Partin, L. R.; Heise, W. H. High-purity methyl acetate via reactive distillation. Chem. Eng. Prog. 1990, 86, 40.

(11) Komatsu, H.; Holland, C. D. A new method of convergence for solving reacting distillation problems. J. Chem. Eng. Jpn. 1977, 10, 292.

(12) Vora, N.; Daoutidis, P. Dynamic and control of an ethyl acetate reactive distillation column. Ind. Eng. Chem. Res. 2001, 40, 833.

(13) Tang, Y. T.; Chen, Y. W.; Hung, S. B.; Huang, H. P.; Lee, M. J.; $\mathrm{Yu}, \mathrm{C}$. C. Design of reactive distillations for acetic acid esterification. AIChE J. 2005, 51, 1683.

(14) Lai, I.-K.; Hung, S.-B.; Hung, W.-J.; Yu, C.-C.; Lee, M.-J.; Huang, H.-P. Design and control of reactive distillation for ethyl and isopropyl acetates production with azeotropic feeds. Chem. Eng. Sci. 2007, 62, 878.

(15) Lee, J. W. Feasibility studies on quaternary reactive distillation systems. Ind. Eng. Chem. Res. 2002, 41, 4632.

(16) Dimian, A. C.; Omota, F.; Bliek, A. Entrainer-enhanced reactive distillation. Chem. Eng. Process. 2004, 43, 411.

(17) de Jong, M. C.; Zondervan, E.; Dimian, A. C.; de Haan, A. B. Entrainer selection for the synthesis of fatty acid esters by entrainerbased reactive distillation. Chem. Eng. Res. Des. 2010, 88, 34.

(18) Wang, S. J.; Huang, H. P. Design of entrainer-enhanced reactive distillation for the synthesis of butyl cellosolve acetate. Chem. Eng. Process 2011, 50, 709.

(19) Patidar, P.; Mahajani, S. Entrainer-based reactive distillation for the synthesis of 2-ethylhexyl acetate. Ind. Eng. Chem. Res. 2012, 51, 8748.

(20) Zhang, B. J.; Yang, W. S.; Hu, S.; Liang, Y. Z.; Chen, Q. L. A reactive distillation process with a sidedraw stream to enhance the production of isopropyl acetate. Chem. Eng. Process. 2013, 117, 70.

(21) Cho, M.; Jo, S.; Kim, G.; Han, M. Entrainer-enhanced reactive distillation for the production of butyl acetate. Ind. Eng. Chem. Res. 2014, 53, 8095.

(22) Hauan, S.; Westerberg, A. W.; Lien, K. M. Phenomena-based analysis of fixed points in reactive separation systems. Chem. Eng. Sci. 2000, 55, 1053.

(23) Guo, Z.; Chin, J.; Lee, J. W. Feasibility of continuous reactive distillation with azeotropic mixtures. Ind. Eng. Chem. Res. 2004, 43, 3758.

(24) Lucia, A.; Taylor, R. The geometry of separation boundaries: I. Basic theory and numerical support. AIChE J. 2006, 52, 582.

(25) Bellows, M. L.; Lucia, A. The geometry of separation boundaries: Four-component mixtures. AIChE J. 2007, 53, 1770.

(26) Agarwal, V.; Thotla, S.; Mahajani, S. M. Attainable regions of reactive distillation. Part II: Single reactant azeotropic systems. Chem. Eng. Sci. 2008, 63, 2928.

(27) Lucia, A.; Amale, A.; Taylor, R. Distillation pinch points and more. Comput. Chem. Eng. 2008, 32, 1342.

(28) Amte, V.; Sriharsha, N.; Malik, R; Mahajani, S. Attainable regions of reactive distillation-Part III. Complex reaction scheme: Van de Vusse reaction. Chem. Eng. Sci. 2011, 66, 2285.

(29) Amte, V.; Gaikwad, R.; Malik, R.; Mahajani, S. Attainable region of reactive distillation-Part IV: Inclusion of multistage for complex reaction schemes. Chem. Eng. Sci. 2012, 68, 166.

(30) Lee, J. W.; Westerberg, A. W. Graphical design applied to MTBE and methyl acetate reactive distillation processes. AIChE J. 2001, 47, 1333.

(31) Julka, V.; Chiplunkar, M.; O’Young, L. Selecting entrainers for azeotropic distillation. Chem. Eng. Process. 2009, 105, 47. 
(32) Huang, H.-P.; Chien, I.-L. Choice of suitable entrainer in heteroazeotropic batch distillation system for acetic acid dehydration. J. Chin. Inst. Chem. Eng. 2008, 39, 503.

(33) Chin, J.; Kattukaran, H. J.; Lee, J. W. Generalized feasibility evaluation of equilibrated quaternary reactive distillation systems. Ind. Eng. Chem. Res. 2004, 43, 7092.

(34) Lee, L.; Kuo, M. Phase and reaction equilibria of the acetic acid-2-propanol-isopropyl acetate-water system at $760 \mathrm{mmHg}$. Fluid Phase Equilib. 1996, 123, 147.

(35) Gadewar, S.; Malone, M. F.; Doherty, M. F. Feasible region for a countercurrent cascade of vapor-liquid CSTRs. AIChE J. 2002, 48, 800.

(36) Kang, Y. W.; Lee, Y. Y.; Lee, W. K. Vapor-liquid equilibria with chemical reaction equilibrium. Systems containing acetic acid, ethyl alcohol, water and ethyl acetate. J. Chem. Eng. Jpn. 1992, 25, 649.

(37) Hangx, G.; Kwant, G.; Maessen, H.; Markusse, P.; Urseanu, I. Reaction Kinetics of the Esterification of Ethanol and Acetic Acid Towards Ethyl Acetate; Deliverable 22, Technical Report to the European Commission; Intelligent Column Internals for Reactive Separations (INTINT): Dortmund, Germany, 2001; available at http://www.cpi. umist.ac.uk/intint/NonConf Doc.asp (accessed Feb 2014).

(38) Hauan, S.; Ciric, A. R.; Westerberg, A. W.; Lien, K. M. Difference points in extractive and reactive cascades. I-Basic properties and analysis. Chem. Eng. Sci. 2000, 55, 3145.

(39) Lee, J. W.; Hauan, S.; Lien, K. M.; Westerberg, A. W. Difference points in extractive and reactive cascades. II-Generating design alternatives by lever rule for reactive systems. Chem. Eng. Sci. 2000, 55, 3161. 